\title{
A Psychotic Reaction to Dental Care A Case Report
}

\author{
Samuel A Nigro* \\ School of Medicine, Case Western Reserve University Ohio, USA
}

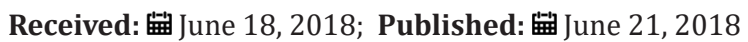

*Corresponding author: Samuel A Nigro, School of Medicine, Case Western Reserve University Ohio, USA

\begin{abstract}
Behavioural reactions to dental procedures have not received sufficient attention in either the psychiatric or dental literature. In medicine, behavioral reactions have been studied in relation to many types of medical and surgical procedures [1-7]. In dentistry, behavior in the dentist's office has been studied and related to maternal anxiety and to previous dental or medical trauma [8,9]. Behavior after the dental office visit has not received much emphasis, nor have adverse behavioral reactions been described as squeal to dental procedures. The patient to be described may represent an extreme example of an adverse reaction to a series of dental procedures, but the case is worthy of note.
\end{abstract}

\section{Report of a Case}

D.D.S. was first seen in early 1971 after his parents sought psychiatric help for this twelve year old male seventh grader who had been having school problems of increasing unacceptability. At the time of the psychiatric evaluation, he was said to be, on the one hand, very aggressive, provoking peers much bigger than he. On the other hand, he often huddled in an isolated fashion and hid himself fearing his same-sized classmates would hurt him. Ile frequently was involved in minor stealing events. In addition, he bit children; threatened others with scissors; kicked classmates for no apparent reason and threw furniture about rooms at school. On one unsupervised occasion, he took a volley ball and threw it around the gym after covering it with paint left by a workman who had taken a coffee break. Such had been his behavior since he started school with progressive unacceptability culminating in the school's refusal to allow him to return after the paint in the gym incident. When confronted with his behavior by adults, he was typically unconcerned as if wondering "why all the fuss?" His general misbehaviour was considered bizarre, inappropriate, and without reason. At no time was he considered vindictive nor argumentative once an adult obtained his attention.

Academically, he was very poor in areas, especially reading. He cheated and copied with little surreptitiousness. For years, a report card in the conventional sense could usually not be given, although, on occasions, he had managed "Cs". He was said to have been advanced from grade to grade on an age basis and not because of academic achievement. From first grade through sixth grade, school adjustment had been accomplished only because of supporting efforts from parents and teachers, but school had always been a problem starting with mild aggressiveness in first grade. The parents stated, "He did okay until school started and it is just get-ting worse and worse." Extracurricular activity was erratic, doing well in swimming and being a "home run hitter" in baseball; but he was a "terrible" boy scout, and the scout troop "wanted him out." At home, he was considered overactive most of the time but slow in doing what was requested. He would often sit quietly watching television for long periods. In the neighbourhood, he was considered to be a "runner"; that is, he would pick on others and then run home. His relationship with his eight year old brother, the only sibling, was no problem. The main problem at home was considered to be his lying, which was, in fact, either a confabulation to explain his misbehaviour at school or a distortion of what he had observed on television, in the home, or around the neighbourhood.

Thus, the parents felt he needed close supervision so they knew the facts in contrast to the child's stories. The past history obtained was generally benign. Pregnancy and birth were uneventful except for brief bleeding (spotting) by the mother for about two weeks during the third month of gestation. He was called a "good baby." Developmental landmarks of walking, talking, and toilet training were attained at ages within the normal range. Medical problems were limited to a few episodes of bronchitis not requiring hospitalization or intensive treatment. A tonsillectomy performed 
at age three required a one-day readmission due to some bleeding two days after his initial discharge from the hospital. Dental care seemed unusual insofar as he had a complete extraction of all primary teeth between the ages of six and eight "because they were too big to come out by themselves." These dental extractions were performed, one or two teeth at a time, under local anesthesia. The parents estimated the number of visits to the dentist for these extractions to be about fourteen or fifteen. They chuckled as they related his initial terror with these procedures but proudly reassured me that "he got over it just fine after the fourth or fifth visit." This dental history seemed unusual, but both parents were absolutely certain of the facts as presented. Efforts to con-tact the dentist were unproductive. Family history revealed a lower middleclass setting without obvious problems in either parent except their appropriate concern and bewilderment about the child's behavior. Medical problems were denied in both parents and in the brother. Mental illness was denied in both sides of the parents' families. In general, the parents were blunt, candid, concerned people of normal capabilities, loving but not warm as they presented themselves to me. They were psychologically unsophisticated in their approach to significant events and the emotional impact of these events. For example, neither the tonsillectomy nor the dental procedures were considered to be of any emotional importance. The brother was not seen in the evaluation, but he was said to be without problems, obtaining "B" grades in school, and well adjusted in all areas.

Medical evaluation had been completed by a pediatrician and neurologist just prior to this psychiatric evaluation. Both the general and neurological examinations were normal. Electroencephalogram was normal. A trial of dextrose amphetamine had made him worse, and a one month empirical trial of dilantin had been without beneficial effects. Psychological testing revealed average intelligence with no marked perceptual or motor impairment. He did have a low attention span, a tendency for impulsiveness, and a general immaturity. Trends of hostility and aggressiveness were also prominent on the testing, and he had a tendency to see others as threats with many references made to destruction. Psychiatric interviews revealed him to be a thin, pale, alert child, actively thinking, and talkative, but strangely blase in his emotional presentation. He was circumstantial in his responses, concrete in his spontaneous comments which were about objects in the room, and distant in his social relatedness; talking past me rather than to me. Verbalizations were deviant and confusing at times, but not to the child, who rambled free-ly and, seemingly, with confidence. He recognized he had problems which, in his words, were temper and using fists. Efforts to discuss his school behavior were met with themes of danger and threats from others that were striking in their non specificity when compared to the wealth of specific events known from the history. He also related his fantasies of getting hurt and of bodily harm. Because of the severity of the problems and of his presentation, which was psychotic in this observer's opinion, medications were prescribed and arrangements made for psychiatric hospitalization.

\section{Comment}

Several factors may account for this child's severe emotional disturbance. First, the mother's brief spotting during the third month of gestation could conceivably have damaged the child. But this seems an unlikely determinant and an improbable contributing factor due to the fact that such bleeding has generally proved harmless. In addition, physical and neurological examinations were normal, and the desperate trials of the stimulant and anticonvulsant were ineffective. Second, the tonsillectomy at age three must have been upsetting because any medical procedure is $2 t$ trauma for a young child. The rebleeding episode after the tonsillectomy must have made this operative procedure even more tublin and difficult to assimilate. However he was not much of a problem until first grade, some three years after the tonsillectomy. Nevertheless, the tonsillectomy could have sensitized the child to the trauma of the extensive dental procedures. Third, the extractions of all primary teeth under local anesthesia between the sixth and eighth birthdays must have been a significant series of traumata for a child of that age. To grasp the impact of such a series of extractions, it may be helpful to read Schwartz's description of psycho-logical factors in the practice of dentistry: resistance, fear, dental anxiety, the significance of the oral cavity, regressive behavior, transference, motivating factors, attitudes of the dentist, symbolism, and understanding the patient [10]. These factors were discussed as relevant to behavior primarily within the dentist's office, although Schwartz briefly mentioned the tendency of children in their play with peers to symbolically recreate, live over, and thereby rid themselves of traumatic ideas about their dental experiences.

For this child, it seems probable that mental mechanisms had been adopted which allowed the child to face these extractions. The degree of the trauma resulted in a firm entrenchment of these mechanisms. However, these same mental mechanisms were maladaptive for behavior out of the dentist's office. One might even see the child's abnormal behavior as an effort to recreate, live over, and thereby rid himself of the traumatic ideas about the dental experiences in line with Schwartz's formulation; only this child's efforts became established patterns with the original dental traumata repressed, and the originally useful mental mechanisms persisted as habits even though the original need for them was no longer present. The fourth factor to consider is the parents' general low level of warmth as noted in their interview. Such lack of warmth may be characteristic of their approach to their children at home and, together with their psychologically unsophisticated approach to events of emotional significance, may indicate a low capacity

to assuage the emotional insults associated with the tonsillectomy and the dental extractions. Which factor, if any, is primarily responsible for this child's disturbance is problematical? A combination, particularly of the last three factors, seems most likely with the dental events being salient. Since little reference to dental procedures being potential long-lasting emotional traumata is in the literature, this one case may serve to emphasize that all those in 
the healing arts, including dentists, must be aware of the impact of procedures, particularly if the parents' capacity for warmth seems low and if the parents have a tendency to automatically accept procedures as routine and without emotional significance. When a dentist must subject a child to an extensive series of procedures, he might well spend time with the parents to gauge their abilities to help the child cope, especially when previous medical traumata have occurred. A referral to a social worker, psychologist, or child psychiatrist may prove helpful; particularly if deterioration in school performance appears to temporally parallel the dental procedures. That the successful provision of dental care includes more than the technical completion of a procedure on a cooperative patient, has been recognized by the official organizations of dentistry for many years. This one case report underscores this recognition, because it may demonstrate the adverse effects resulting when efforts to provide dental care in a psychologically sound manner are not forthcoming. Horn the Child Psychiatry Division. Department of Psychiatry. Case Western Resent University School of Medicine and University Hospitals. Cleveland. Ohio 44106.

\section{References}

1. Freud A (1952) The Role of Bodily Illness in the Mental life in Children. Psychoanal Stud child 7: 69-81.
2. Miller ML (1951) The Traumatic Effect of Surgical Operations in Childhood on the Integrative Function of the Ego. Psychoanal Quart 20(1): 77-92.

3. Pearson GH (1941) Effect of Operative Procedures on the Emotional life Of the Child. Amer J Pis Child 62(4): 716- 729.

4. Vernon DTA, Schulman JL, Foley JM (1966) Changes in Children Behavior after Hospitalization. Amer J Dis Child 111(6): 581-593.

5. Prugh DG (1953) A Study of the Emotional Reactions of Childress and Families to Hospitalization and Illness. Amer J Orthopsychiat 23(1): 70.106 .

6. Abram HS (1969) Psychological Response lo Illness and Hospitalization. Psychosomatics 10:218-224.

7. Mattsson A, Weisberg I (1970) Behavioral Reaction to Minor Illness in Preschool Children. Pediatrics 46(4): 604-610.

8. Johnson Ronald (1971) Maternal Influence on Child Behavior in the Dental Serving. Psychiatry Med 2: 221-228.

9. Cramer EH, Szmyd L (1962) Identifying the Overly Anxious Patient in Impacted Third Molar Surgery, SAM-TDR, School of Aerospace Medicine, Aerospace Medico Division (APSC) 62: 90.

10. Schwartz W (1971) Psychological Factors in the Practice of Dentistry. J Amer Coll Dent 38(3): 161-172.

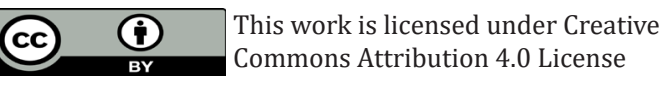

To Submit Your Article Click Here:

Submit Article

DOI: $10.32474 /$ IPDOAJ.2018.01.000124

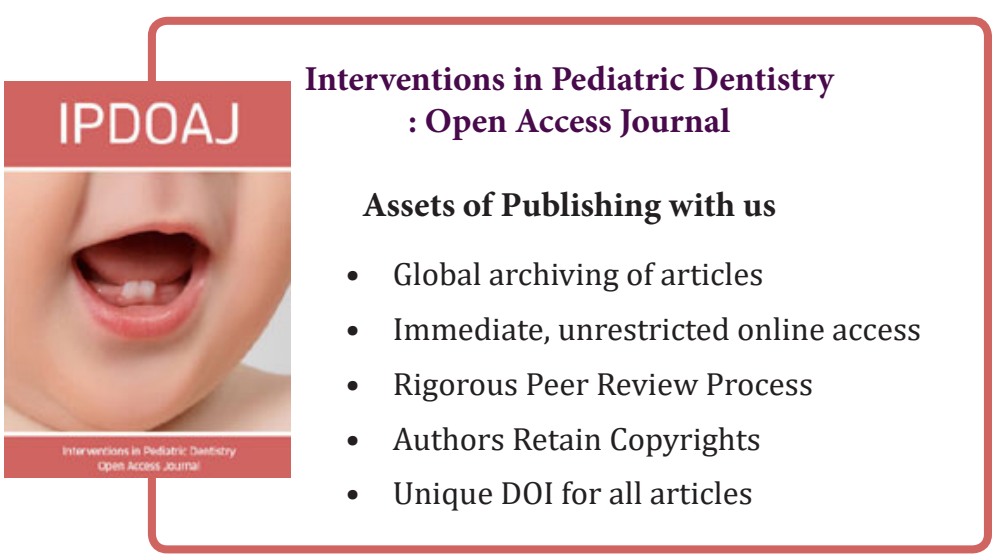

